In dentistry we had flirted with the idea

of auxiliaries but this tag was seen as far

too demeaning. Looking to the medical

model, the first attempt was Professions

Supplementary to Dentistry, as in

Professions Supplementary to Medicine.

However, this was immediately felt to

undermine the value of the contribution

that these team members made.

\title{
What's in a name?
}

What's in a name? That which we call a rose

By any other name would smell as sweet.

Romeo and Juliet Act II, Scene II.

When Juliet utters these words she has just learnt that Romeo is a Montague and is in the process of urging him to refute his name for the pragmatic reason of their being able to be together. Centuries later, albeit with the romantic imperative removed, the problem of wrestling with the cultural importance of names remains as real as on that famous balcony. I refer to the debate of growing heat, intensity and emotion surrounding the designation; professional complementary to dentistry (PCD).

The name arose from the need to find a shorthand term suitable to describe the various categories of personnel who would form the dental team of the future, which is not to say that they were not already forming the dental team of the time. Listing the various job titles; dental hygienist, dental nurse, dental technician, dental therapist was tedious and clearly too much of a mouthful, so the search was on for a politically correct, suitably succinct and generally recognisable collective title.

In dentistry we had flirted with the idea of auxiliaries but this tag was seen as far too demeaning. Looking to the medical model, the first attempt was Professions Supplementary to Dentistry, as in Professions Supplementary to Medicine. However, this was immediately felt to undermine the value of the contribution that these team members made, being integral to the delivery of dental care and not supplementary to it. We then moved to professions complementary to dentistry, as an improvement and thence to the refinement of professionals, the difference being subtle but distinct.

While not perhaps the most elegant of terms, this has stood the test of time at least for the meanwhile.
However, there is an agitated sense that this might not be the best appellation to carry forward. So what else is there? Oral Health Practitioners (OHP) is a current front runner but the problem is that such a title then requires an explanation. The familiarity of dental nurse, dental hygienist and so forth are descriptors that instantly conjure an image of a person and a service in the way that OHP does not. Conversion to the use of such a term would then require a further explanation as to function. In addition, I cannot help feeling that it also has that ring of unnecessary aggrandisement about it that makes 'executive retail operative' a less satisfactory term for all its apparent promotion than the honest label of shop assistant, to which we can all relate.

In the global scale of things there are more pressing matters regarding PCDs to which we still need to attend. The process of registration with the attendant complexities of ensuring correct qualification, grandparenting arrangements and so forth; the increasingly raised question of continuing professional education and development for the newly registered PCDs also still requires much work. Yet, as in many matters, what one is called is a feature not just of daily pleasantry but a fundamental issue of hierarchy and the way in which we 'see' ourselves in relation to our other colleagues and the profession as a whole.

They may be just words but they are essential words for, and words essential to, our identity. Until we can agree that identity among ourselves we cannot expect others such as patients, public, media and politicians to either understand our relationship to one another or indeed to respect our collective voice when we choose to, or need to, use it.

Stephen Hancocks OBE, Editor-in Chief doi: 10.1038/sj.bdj.4812579 